\title{
Dorothy e o mágico consumo de Oz
}

\author{
Alberto Cipiniuk \\ Maria Luiza Zenobio de Assumpção Villar Laufhütte
}

\section{Pela estrada dos tijolos amarelos}

$\mathrm{E}$ stabelecido na cidade de Washington, O National Museum of American History é um dos sítios mais visitados da Smithsonian Institution. Possui mais de três milhões de objetos que representam e preservam a história americana e, portanto, "(...) as coleções do museu refletem as diversas experiências, crenças e sonhos que moldaram a nação" (Kendrick; Liebhold, 2006: VI). Encontram-se no local objetos que honram as vidas e as realizações de indivíduos célebres, como o cachimbo que pertenceu a Albert Einstein - lembrando que mesmo de nacionalidade alemã, foi radicado nos EUA -, as luvas de Marylin Monroe e a corneta usada na infância de Louis Armstrong.

Deste modo, o museu também revela objetos que são considerados preciosos, pois estão associados a momentos críticos da expansão social e política dos EUA, como a escrivaninha utilizada por Thomas Jefferson para escrever a declaração de independência e o balcão de lanchonete no qual os estudantes sentaram-se para protestar contra a segregação racial em Greensboro, no Estado da Carolina do Norte. Enfim, objetos que curadores, museólogos e o público consideram importantes para compreensão da história norte americana.

A instituição também explora objetos ligados às tradições culturais, descobertas científicas, invenções tecnológicas e algumas criações artísticas, porém fora daquilo que nós convencionamos chamar obras de arte, como pintura, escultura e gravura. Por meio da preservação desses objetos e ao compartilhar suas histórias, o museu pretende ajudar na percepção dos cidadãos americanos sobre o valor de 
seu patrimônio e garantir que os mesmos continuem a inspirar as gerações futuras (Kendrick; Liebhold, 2006: VI). Estão neste museu os sapatinhos "de rubi", nome dado devido à cor vermelha, da personagem Dorothy do filme O Mágico de $\mathrm{Oz}(1939)$.

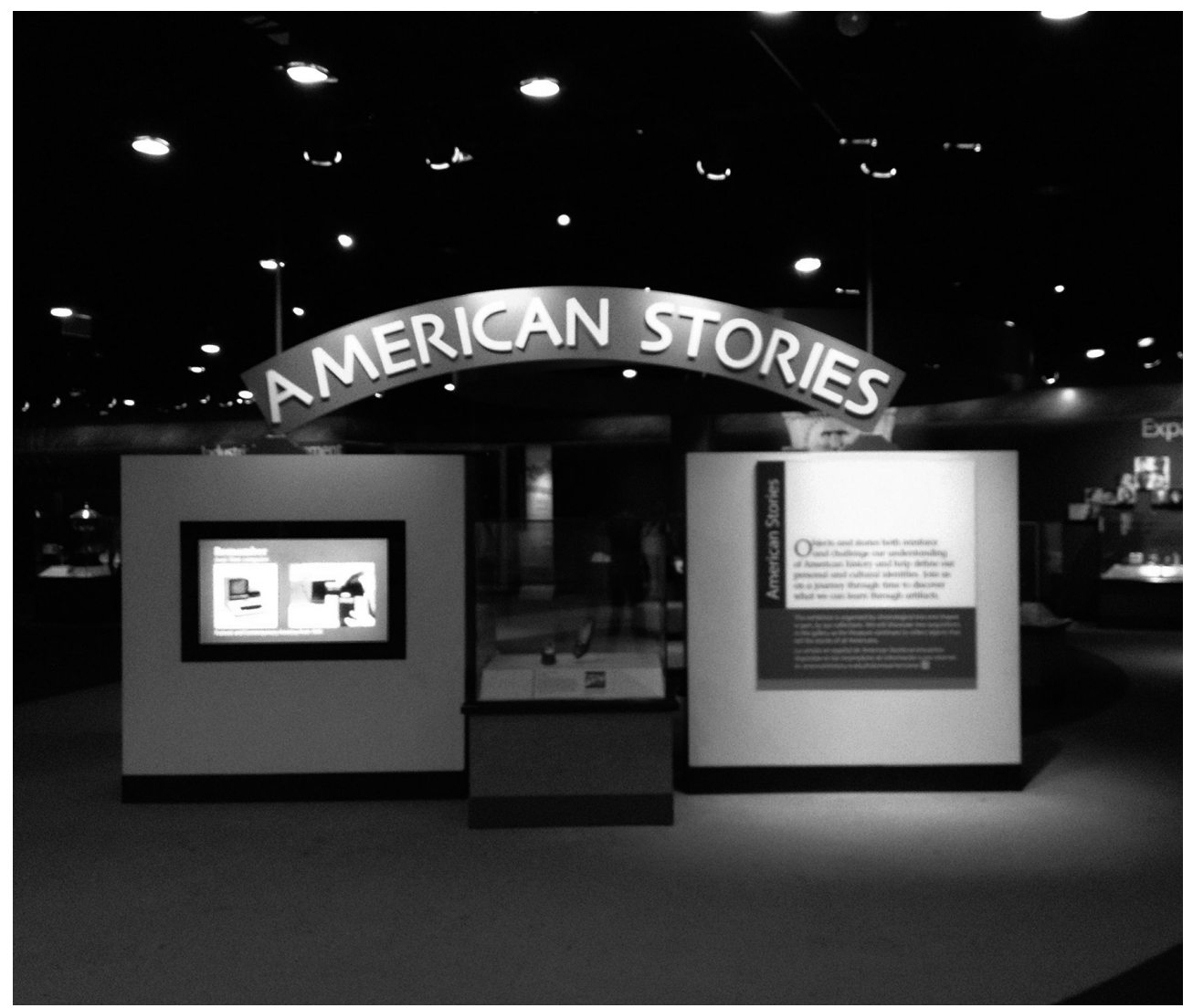

Figura 01 - Entrada da Sala American Stories, 2016.

National Museum of American History.

Fotografia do acervo pessoal dos autores. 


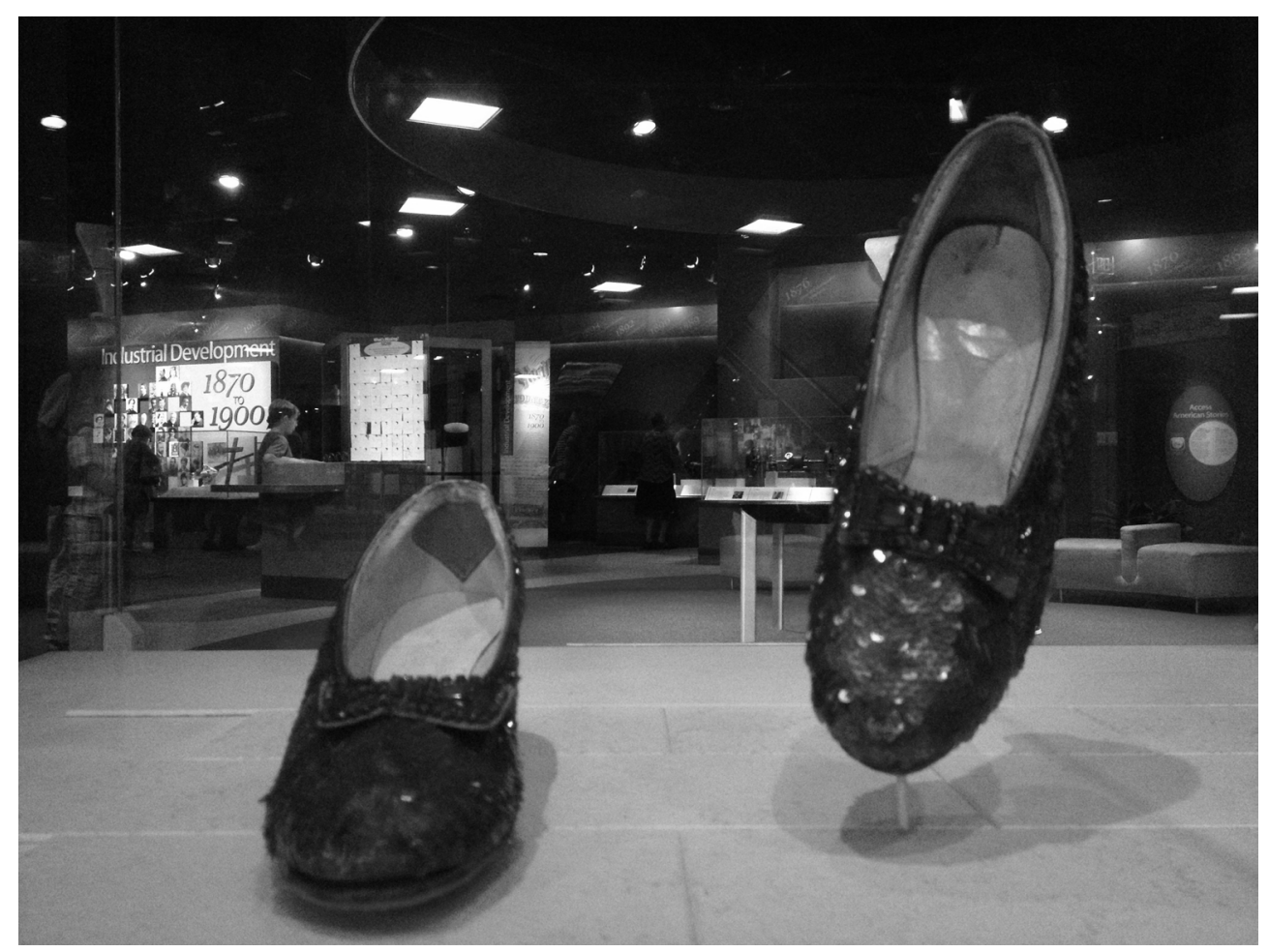

Figura 02 - Os sapatinhos de Dorothy, 2016.

National Museum of American History.

Fotografia do acervo pessoal dos autores.

Como parte mais sofisticada desta instância de legitimação da estrutura social, o museu, são duas as lojas que vendem produtos associados a tudo visto pelo visitante no seu interior. A primeira, situa-se no andar onde está também localizada a entrada principal do local. A segunda, no andar inferior, é enorme. Há uma seção grande dedicada ao $\mathrm{O}$ Mágico de $\mathrm{Oz}$ com inúmeros artigos como chocolates, bolsas, blusas, itens de decoração de Natal, brinquedos, bonecas, conjunto de saleiro e pimenteiro, entre outros. Todos esses "produtos" ou, se desejarmos, objetos da cultura material, são mercadorias que estão lá para serem comercializadas, isto é, serem consumidas, pois o estatuto ontológico de hoje poderia ser resumido em uma frase calcada em Descartes: consumo logo existo. 


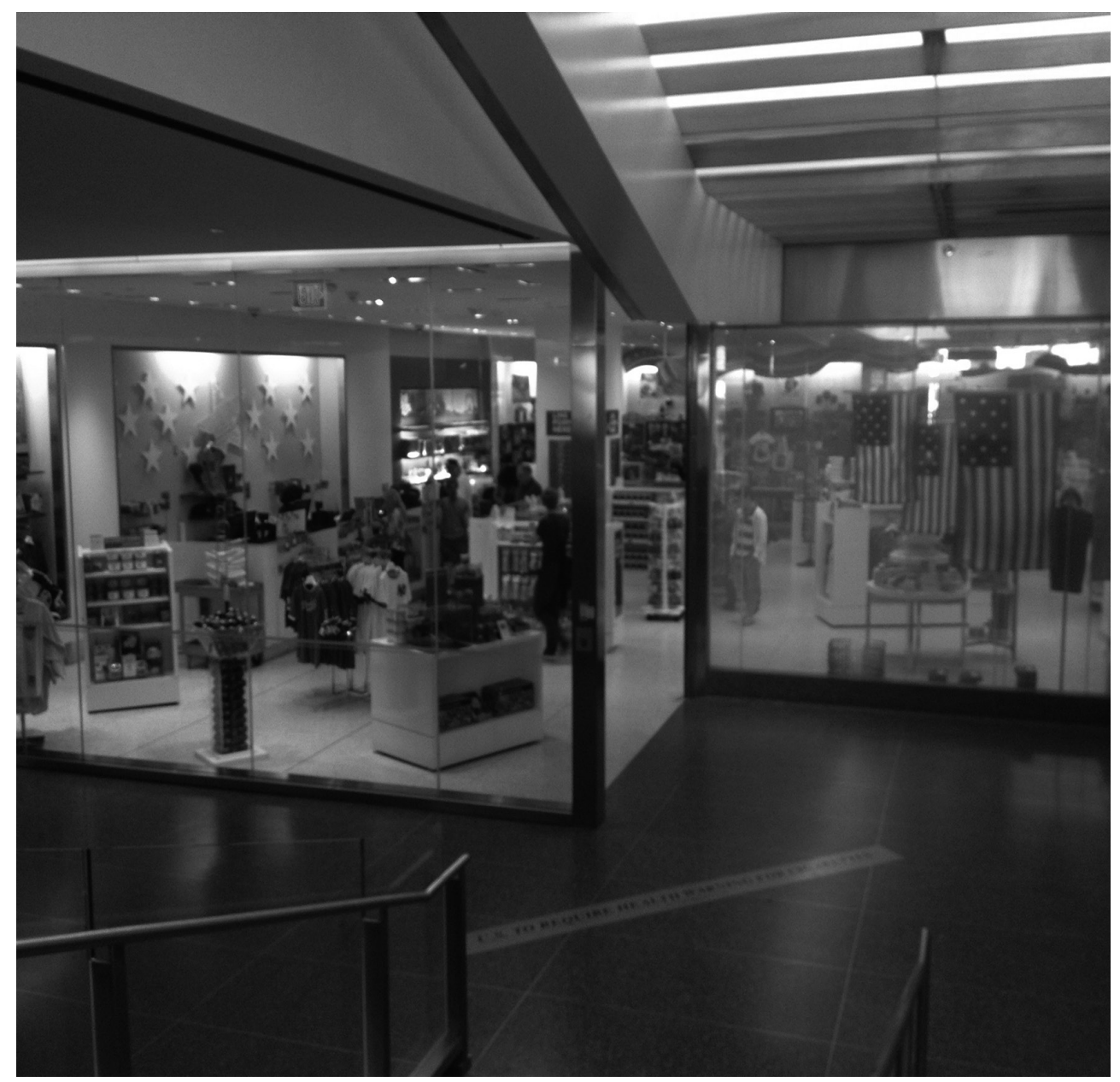

Figura 03 - Loja localizada no andar inferior, 2016.

National Museum of American History.

Fotografia do acervo pessoal dos autores. 


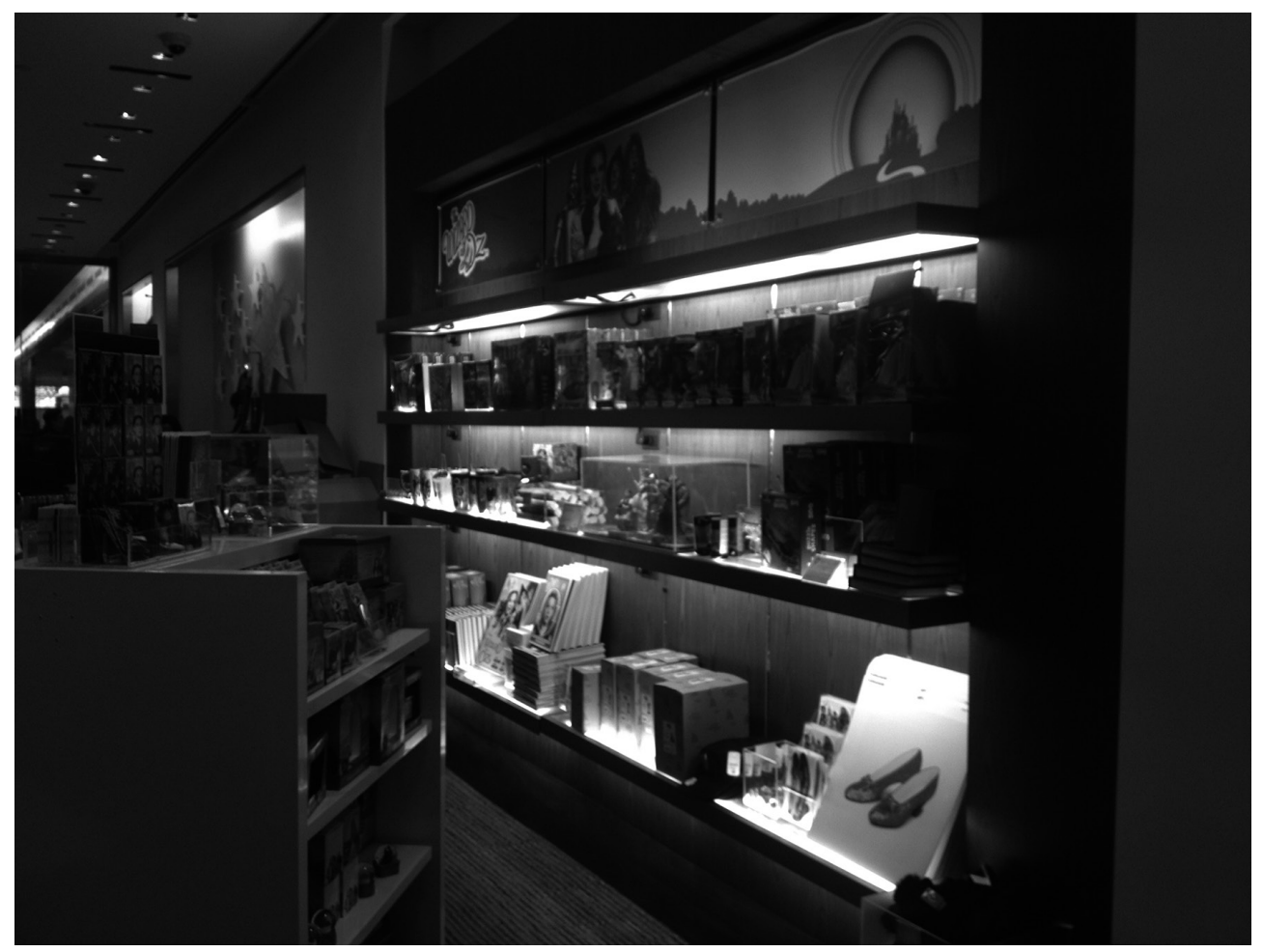

Figura 04 - Interior da loja, 2016.

National Museum of American History.

Fotografia do acervo pessoal dos autores.

Verificamos que os aspectos da proposta do sociólogo Pierre Bourdieu sobre a noção de habitus são apropriáveis no que diz respeito ao consumo. Este seria, sob certo ponto de vista, um sistema de representação simbólico dos grupos sociais. Bourdieu (1983) especulou sobre o meio social, a cultura e o universo simbólico nos quais o objeto está inserido.

Com o tempo, as casas e os indivíduos passaram a ser adornados com os objetos que, atualmente, são vendidos aos milhares diariamente, atuando como mediadores das próprias relações humanas, ou ainda, como intermediários entre o homem, suas vontades e seus desejos. E é nessa medida que abordaremos, primeiramente, as relações entre objetos e consumidores a partir do Campo do Design.

\section{O campo do Design e a experiência do consumo}

De acordo com a vertente teórica por nós empregada, o campo do Design inicia a sua constituição a datar da segunda metade do século XVIII, mais precisamente a 
partir da Revolução Industrial, a qual ofereceu as condições de possibilidade para o desenvolvimento de um novo campo de atividade profissional para um conjunto de novidades tecnológicas, assim como para as novas necessidades sociais que surgiram ao longo deste período histórico, tal como descreveu Adrian Forty (2007: 22) no livro Objetos de desejo.

Forty (2007: 12) relatou que, em relação aos artefatos industriais, a palavra design poderia assumir dois significados principais. O primeiro se referiu à aparência ou à forma dos objetos que era determinada sob julgamentos relacionados às noções de beleza. O segundo sentido foi relacionado à preparação de instruções de racionalização para a produção de bens manufaturados, isto é, o primeiro se reportava à dimensão estética e o segundo à dimensão utilitária do objeto industrial. De acordo com esses sentidos ou significados, fica claro que seria um enorme desacerto desmembrá-las, pois a palavra design manifesta, em um sentido mais amplo, que a aparência dos objetos é uma consequência das condições de sua produção, ou seja, que a sua dimensão material não pode ser apartada da sua dimensão simbólica. Não se trata, portanto, de opor uma e outra, mas de entendê-las como complementares. Paralelamente, um dos aspectos importantes trazidos por Forty em Objetos de desejo, foi a situação histórica onde o fenômeno design ocorreu pela primeira vez, pois estabelecendo-o como parte integrante do sistema de produção de bens manufaturados originário do sistema capitalista, ficava subentendido que a fabricação de objetos industriais visava o lucro para o fabricante e que o design não possuía unicamente o objetivo de torná-los belos ou funcionais, mas também a produção de mais valia. Forty ressaltou que isso que é o design, portanto, é uma prática social encarregada de criar ou produzir os objetos, principalmente, industriais e também o próprio "desejo" de consumo por tais objetos. Aliás, esse é o título do livro de Forty que, de modo geral, nos perguntou: quem de fato produz o desejo por esse ou por aquele objeto? Essa noção se verificou importantíssima para a abordagem sobre o design, pois ficou claro que o modo de produção industrial constrói não apenas o objeto em si mesmo, mas também o desejo da sua aquisição - a sua necessidade -, assim como outras noções simbólicas que o cercam. Por noções simbólicas entendam-se os processos empregados pelos designers para conquistar o público consumidor por algo ou alguma coisa que tenha ou não tenha valor de uso.

Conforme sublinhado por Forty (2007: 20), a ascensão do capitalismo está inevitavelmente ligada não apenas à produção de objetos industriais, mas à capacidade de "inovar" e vender os produtos. Aliás, inovar, ou o conceito da produção do "novo" com fins comerciais, foi também um produto ou uma tecnologia social produzida pela Revolução Industrial para legitimar a produção de valores ou transformar os antigos valores simbólicos naqueles que interessavam à produção da mais valia. Assim, o design precisa ser compreendido de forma mais ampla, não apenas restrito aos aspectos objetivos do produto, isto é, técnicos, mas também em relação 
à produção das noções simbólicas que o ajudavam a construí-lo, pois elas alteraram substancialmente a forma como percebemos as mercadorias. Há algo muito além da função e da finalidade utilitária dos objetos a ser investigado. Ou seja, o valor de uso pode ser examinado a partir de seus significados, suas funções e seus aspectos visuais.

Os teóricos do campo do Design observaram que os objetos constituem o entorno e o ambiente próprio de cada indivíduo. No último parágrafo de Objetos de desejo, Forty (2007: 330) escreveu: "Este livro (...) pretendeu mostrar os modos pelos quais o design transforma ideias sobre o mundo e relações sociais na forma dos objetos".

Constatamos, conforme explicou Gustavo Bomfim (2014: 23-24), que o design traduz-se em uma atividade representativa tanto dos objetos de uso como de sistemas de informação materializando, através dos mesmos, os ideais, os arquétipos, as convicções e também as contradições e as incoerências de uma sociedade, incorporando uma porção dos valores e manifestações culturais que a compõe. Ademais, o design é componente da criação cultural de uma sociedade e, como tal, é também uma prática social dessa mesma sociedade, expressando ou mesmo denunciando suas perfeições ou imperfeições.

Se desenvolvida especialmente com a Revolução Industrial, a sociedade de consumo ganha agilidade maior ao longo do século XIX, quando se estabelecem os primeiros magazines, famosas lojas de departamentos, nas cidades consideradas importantes e influentes tanto na Europa quanto nos Estados Unidos, descreveram os autores do livro O paraíso do consumo: Émile Zola, a magia e os grandes magazines (Rocha, Frid e Corbo, 2016: 43). Consumir passa a significar o desenvolvimento econômico e elemento de mediação das variadas relações que se estabelecem na sociedade da época que foi arrebatada pelas experiências do consumo estabelecendo uma estreita relação com os bens adquiridos (Rocha, Frid e Corbo, 2016: 131).

Se "no 'espaço comunicacional' inaugurado pelas lojas de departamentos, os produtos ganhavam revestimento simbólico e incorporavam identidades capazes de descrevê-los, classificá-los e posicioná-los no sistema geral de bens" (Rocha, Frid e Corbo, 2016: 169), observa-se que o mesmo "ambiente mágico" é copiado nos espaços atuais, incluindo aí as lojas inseridas nos museus que oferecem ainda uma posição de maior destaque para o consumidor que visitou um ambiente ilustre e que comprova sua passagem pelo local carregando consigo algum mimo da lojinha. O próprio museu é por excelência um ambiente que potencializa o mágico consumo de objetos.

Constatamos que os objetos se tornaram integrantes das nossas atividades frequentes. Na prática do consumo, baseiam-se as novas relações estabelecidas entre os objetos e os sujeitos sociais, nas quais a importância dos mesmos é cada vez mais valorizada pelas pessoas. Desenvolveu-se uma enorme gama de objetos disponibilizada ao consumidor e, na verdade, verifica-se que não existe mais a perspectiva do simples ato de comprar uma mercadoria somente pela sua finalidade de uso sem a possibilidade do poder da sua escolha. Em vista disso, a eleição de determinado objeto 
torna-se significativa, pois sua escolha personaliza seu proprietário. Desta forma, "o consumo (...) constrói categorias e relacionamentos, marca diferenças e semelhanças capazes de atribuir alguma espécie de ordem à vida social" (Rocha, Frid e Corbo, 2016: 190). Tal indivíduo insere-se, sobretudo, em um grupo de determinada ordem sociocultural, unindo-se aos seus semelhantes e diferenciando-se das demais classes sociais, imprimindo projetivamente aos objetos determinados significados através do seu uso social, ou seja, aquilo que já está legitimado pelo habitus.

Reexaminando os fundamentos da sociologia, Pierre Bourdieu objetivou debater as relações de poder e, por conseguinte, também de dominação existentes em suas suposições teóricas acerca de estruturas sociais, concebendo certas noções, sendo as mais relevantes as noções de habitus e campo. Entendemos que tais noções são essenciais para o conhecimento e entendimento da investigação feita por Bourdieu e ora articulam-se juntas, ora separadas.

Bourdieu (1983) retomou a noção de habitus, originada na escolástica medieval, e a desenvolveu como uma organização de disposições nas nossas formas de pensar, sentir e agir. O sociólogo explicou que o termo "disposição" parece especialmente adequado para expressar com efeito a noção de habitus, compreendida tal qual um "sistema de disposições", pois expressa, primeiramente, a consequência de uma ação organizadora, expondo assim um sentido aproximado ao de palavras como estrutura, por exemplo. Sob outra perspectiva, o termo indica "uma maneira de ser, um estado habitual (em particular do corpo) e, em particular, uma predisposição, uma tendência, uma propensão ou uma inclinação" (Bourdieu, 1983: 61).

Tais disposições ou habitus são socialmente estruturadas e mentalmente estruturantes para cada sujeito que compõe uma sociedade específica. Foram elas analisadas por Bourdieu como flexíveis, ou seja, condicionáveis às estruturas sociais, isto é, estão situadas no tempo e no espaço, tornando-se dinâmicas. Desta forma, o que serve como exemplo em um determinado lugar não serve para outro. O habitus se parece com algo crônico e enraizado no nosso dia a dia que emerge aleatoriamente em nossas ações e em comportamentos que não percebemos racionalmente. Pensamos antes de agir ou simplesmente agimos? Trata-se de um processo, supostamente, "natural" do qual muitas vezes não temos mais consciência e nos parece rotineiro na nossa existência. Simplesmente o reproduzimos. É criado um sistema de disposições e um discurso coeso apto a proporcionar e assegurar o domínio simbólico dos princípios praticados pelos sujeitos de cada classe social em particular (Bourdieu, 1983: 76).

O habitus reproduz as práticas específicas de uma classe social da estrutura social, gerando códigos próprios a esta classe e criando uma lógica para os comportamentos sociais de modo geral, tal como o modo como cumprimentamos alguém na rua, a forma como nos portamos à mesa e também em relação às operações mentais ou intelectuais sem refletirmos, mas simplesmente através das nossas ações. Bourdieu (1983) observou que pertencemos às estruturas sociais, ou seja, somos 
agentes destas estruturas, e carregamos desde o nascimento até a morte o habitus, este universo simbólico construído por cada campo especificamente.

A noção de campo apresentada na obra de Bourdieu (1983: 44-45) foi explicada como um espaço de conflito estruturado por dominantes e dominados, cuja estrutura é reforçada pelos próprios agentes participantes e ativos na mesma. Tal noção, pode ser identificada em diferentes campos, como, por exemplo, no Campo do Design. O campo, portanto, não deve ser entendido como uma estrutura fixa. Sua existência é demarcada pelos interesses específicos, como aqueles de ordem econômica por exemplo, dos agentes que possuem o mesmo habitus. O habitus é estruturado pelo campo e o campo é constituído pelo habitus.

Prolongando, desta forma, tais noções de Bourdieu, é possível observar que o consumo de determinados objetos proporciona a relação entre os diversos grupos socioculturais que possuem ou desejam possuir determinados produtos. Consumir revela-se como um processo de mediação de relações sociais, o qual produz valores simbólicos através dos objetos.

Antes de seguirmos, faz-se fundamental o entendimento da posição dos agentes dentro de um campo, pois o seu funcionamento está delimitado à dominação dos participantes que determinam o que está dentro e aquilo que "deve" ficar fora do mesmo. O que seria isso que demarca o monopólio da autoridade destes agentes? O campo é consequência do sistema de categorização agenciado por estes indivíduos que ao mesmo tempo que atuam, são também objetos desta ação social, sofrendo assim os resultados desta atuação, isto é, os agentes são ao mesmo tempo sujeitos e objetos das ações sociais praticadas por eles. As relações de força promovidas pelos agentes e as instituições que lutam entre si no interior do campo, organizam o mesmo e geram a sua estrutura interna, isto é, os seus códigos de referência, os valores as serem respeitados.

O campo, desta forma, é formado pelos agentes da produção, pelos agentes da recepção e pelos agentes de circulação instituídos pelas instâncias de consagração e legitimação. Quem afirma qual obra de arte ou objeto deve e, acima de tudo, pode estar dentro de um museu, por exemplo? Aliás, quem decide o que é uma obra de arte? Para Bourdieu, os agentes dessa legitimação são também os agentes da circulação ou consagração, ou seja, a crítica em si estabelecida por estes mesmos agentes ou pares que operam na definição de cada campo, gerando consequentemente relações de forças entre os próprios agentes que lutam entre si para manter ou assumir desejadas posições dominantes dentro do mesmo. Cada campo é uma convenção social e também um processo de diferenciação social, baseado em valores estabelecidos pelos pares, fundado por regras e consolidado por hierarquias.

Ainda que talvez possamos discutir em qual medida o cachimbo de Einstein exposto no National Museum of American History possa honrar a sua própria 
existência, é preciso lembrar que quem adjetiva como honra e celebração certos objetos é a própria sociedade. O museu é uma instituição social de consagração social e seus diretores enquanto agentes de consagração, assim como o público, participam do processo de legitimação dos homens e mulheres mais excelentes de cada período histórico.

\section{A instituição museu}

Assinalado pela oposição entre os novos valores e as regras passadas em vigor na Idade Média, entre o paradoxo da Reforma e a insistência das normas católicas, o século XVI apresentou o caráter inicial do museu conforme o conhecemos até hoje: “(...) um sistema fechado onde os objetos estéticos são agrupados para fruição pelas elites bem pensantes. Desligava-se, desta forma, o artefato estético de sua raiz; saía do mundo para a placidez da sala de exposição”, descreveu Maria Lucia Segall (1991: 69) no livro O museu Lasar Segall na década de 70. É possível notar alguma diferença desta instituição ao longo destes cinco séculos?.

A burguesia consolidava-se na Inglaterra e em 1753 foi fundado o The British Museum na cidade de Londres, o primeiro museu que possibilitava a visitação do público em alguns dias da semana. Outras instituições, como a Royal Society, o Jardin du Roi e a Académie des Sciences por exemplo, também incentivaram o avanço cultural e, ressaltamos, todos eles sob a proteção real. Isto é, os museus, patrocinados pelos reis e suas cortes, operavam como símbolos de status ou distinção social em relação aos mesmos. O fim do Antigo Regime, foi também marcado pela democratização do conhecimento que passou a ser concedido pelas entidades, estendendo o acesso à cultura para mais camadas sociais. Os colecionadores particulares de arte romperam com seus acervos exclusivos ao incorporarem suas peças nos museus públicos. Daí em diante, a crítica às obras de arte é introduzida pelos intelectuais da burguesia (Segall, 1991: 70). Observamos que os agentes de circulação começaram a apontar aquilo que deveria ou não deveria ser legitimado como obra de arte, pois o julgamento dos pares fazia-se presente desde este momento.

O museu obteve a sua institucionalização ou passou a ser entendido como instituição cultural assentido pela sociedade somente no final do século XVIII, isto é, com a Revolução Industrial e a Revolução Francesa. No início do século XIX, seguiram-se os surgimentos de várias instituições, como a National Gallery e o Victoria and Albert Museum entre outras, todas baseadas nos padrões culturais franceses que evidenciavam a cultura nacional (Segall, 1991: 70).

Com a sucessão do aparecimento de vários museus europeus bem como norte-americanos, a burguesia celebrava o capitalismo e os princípios do mesmo dominavam o mercado econômico. As obras de arte foram transformadas em bens simbólicos de trocas monetárias controlados por uma indústria que começava a ser 
determinada pelo capitalismo, formando por sua vez um verdadeiro campo de trocas financeiras, o que induzia obviamente o fazer dos agentes de produção, ratificando o que já foi escrito anteriormente.

A entidade museu e sua prática são partes do conjunto da produção cultural moderna, mais especificamente da produção artística. Ou seja, o entendimento do museu como instituição possuidora de funções sociais faz-se através da compreensão da arte na qualidade de fenômeno social (Segall, 1991: 63). O museu é uma espécie de ferramenta de legitimação ou consagração de certos objetos eleitos os mais valiosos socialmente. Visitá-los nestas instituições significa que os entendemos, que damos valor a eles e, do mesmo modo, eles chancelam à nossa própria condição.

Retomemos o exemplo da posição dos agentes de consagração, como as instituições (museus, galerias, centros culturais etc.), os curadores, os marchands e os críticos. Eles, pessoas dotadas de conhecimento técnico da arte, constroem as convenções do campo e são estes mesmos agentes que definem o que deverá estar dentro ou fora de um museu. Consequentemente, o museu é reconhecido pela estrutura social como um espaço de consagração, legitimando os mais variados objetos.

\section{A consagração dos sapatinhos}

Os sapatinhos de Dorothy são a glorificação da história americana afirmada através do objeto que celebra também o próprio cinema norte-americano, refletindo a soberania hollywoodiana cinematográfica sendo um símbolo deste poder. No livro The Wonderful Wizard of $\mathrm{Oz}$, de L. Frank Baum, os sapatos mágicos de Dorothy eram da cor prata. Contudo, para tirar o máximo de proveito do novo e colorido sistema da Technicolor, processo de coloração de um filme produzido pela gigantesca indústria cinematográfica norte-americana, os sapatos de prata tornaram-se vermelhos como feitos de rubi, pois a cor vermelha objetivou o contraste mais eficaz contra a extensa estrada de tijolos amarelos que demarcava o caminho pelo qual a personagem chegaria ao fantástico mundo de $\mathrm{Oz}$. O objeto pode ser considerado sob diferentes possibilidades, isto é, abordado a partir de uma infinidade de valores ou referências sociais associados ao mesmo. Simboliza ideologicamente, por exemplo, as instituições lar e família, o cidadão americano e sua pátria, pois é através da magia dos sapatinhos que existe a possibilidade de Dorothy voltar para sua casa no Kansas, afinal "there's no place like home". Observamos que tal sentença ficou classificada na vigésima terceira posição na lista do American Film Institute, a qual inclui as cem melhores citações de filmes do cinema norte-americano. Tal classificação também reflete a América idealizada como o local dos sonhos, a terra da liberdade que mesmo entre tantas guerras valida as suas vitórias e o museu reafirma, em cada objeto, a nacionalidade patriótica a todo tempo ao seu visitante a partir do seu próprio nome: The National Museum of American History. Todo o museu legitima a história da América e tudo o 
que estiver exposto lá dentro é consagrado pelos americanos que são influenciados por esta fantástica instituição e por seus agentes de circulação e consagração que lá trabalham. A representação social da nação americana como soberana e a afirmação desta estrutura social é imprescindível para esta instituição. O habitus da estrutura social americana, tanto coletivo como individual, é constituído também deste patriotismo exacerbado, deste sentimento cultivado através de um processo de inculcação de pertencer a esta grande nação influente e tal habitus se reafirma a todo instante através de cada objeto exposto no museu.

As lojas inseridas nos museus já fazem parte das estruturas sociais há algum tempo. Muitos museus pelo mundo afora oferecem mercadorias associadas ao que está exposto ou a algum artista específico. Os objetos desta natureza são intensamente comercializados, pois é constatada a "necessidade" do indivíduo de fazer parte de alguma coisa, mesmo que seja pela obrigação de se sentir adequado a uma estrutura social, de participar das trocas simbólicas que as outras pessoas estão participando, ou seja, consumindo alguns dos mimos da lojinha.

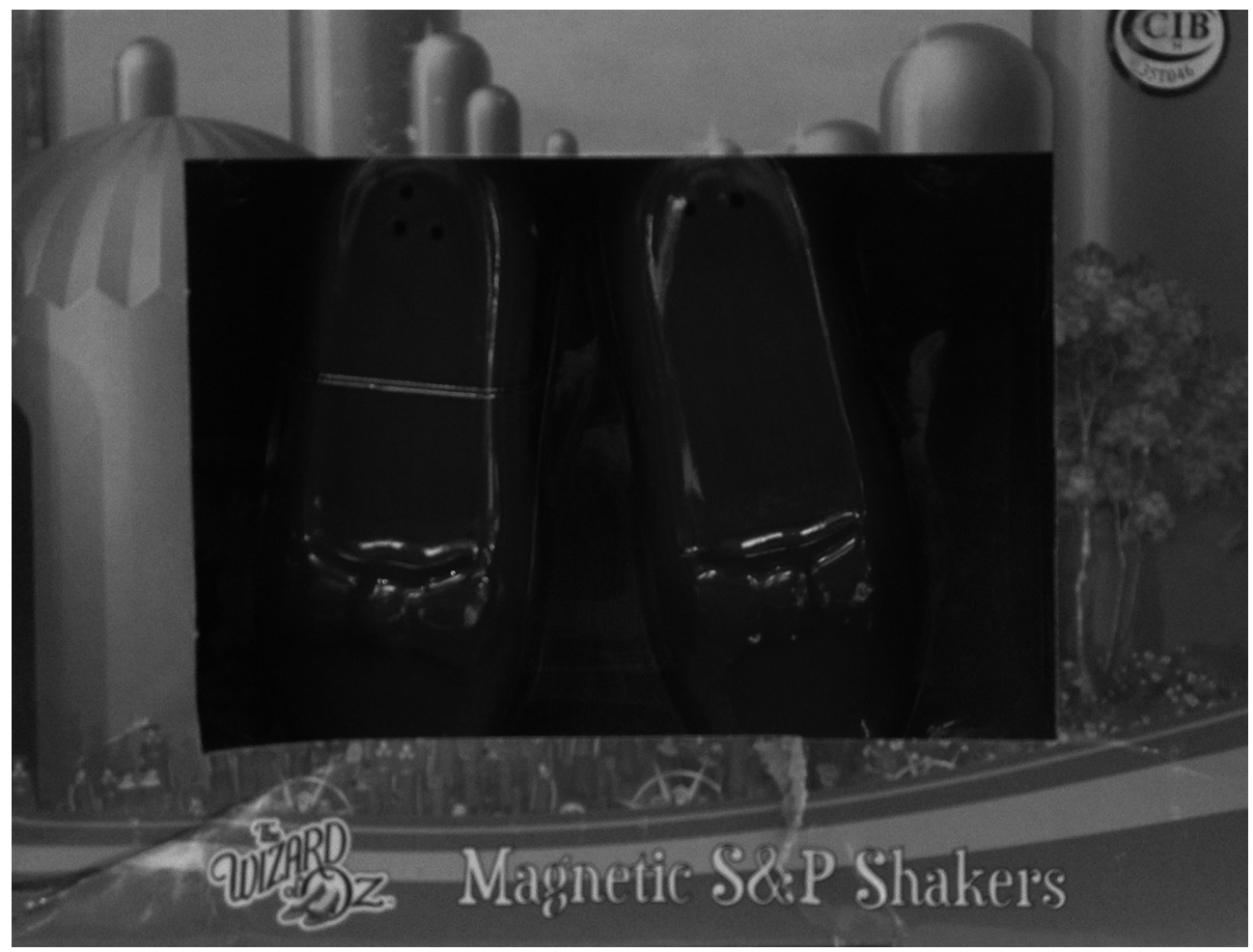

Figura 05 - Conjunto de saleiro e pimenteiro, 2016.

National Museum of American History.

Fotografia do acervo pessoal dos autores. 
Curioso pensarmos que conforme abordado na análise de Stuart Culver sobre O Mágico de $\mathrm{Oz}$, uma das possíveis interpretações acerca do filme poderia tratar-se de "uma visão moralista do consumo" (Rocha, Frid, e Corbo, 2016: 217). Os sapatos da Dorothy alcançaram a categoria de um referencial da história norte-americana e o conjunto de saleiro e pimenteiro, da imagem acima, pode ser adquirido por menos de vinte dólares.

\section{Alberto Cipiniuk \\ Professor da Pontifícia Universidade Católica do Rio de Janeiro (PUC-Rio) Doutor em Filosofia e Letras (Université Libre de Bruxelles) \\ Maria Luiza Zenobio de Assumpção Villar Laufhütte Doutoranda em Design (PUC-Rio)}

Recebido em março de 2018.

Aprovado em agosto de 2018.

\section{Notas}

1. Fundada em 1846 e situada em Washington DC - USA, a Smithsonian Institution inclui 19 museus e galerias.

2. “(...) the Museum's collections reflect the diverse experiences, beliefs and dreams that have shaped the nation"

3. The Wizard of $\mathrm{Oz}$ [feature film] Dir. Victor Fleming. Metro-Goldwyn-Mayer, 1939. 101 mins.

4. Campo do Design, Campo do Cinema ou Campo da Arte, por exemplo, são termos técnicos formulados por Pierre Bourdieu (1983) e por essa razão grafados em letra maiúscula.

5. Na verdade, Bourdieu prefere empregar o termo "lugar social" ao invés de "classe social". Ele considera que o termo "classe" é mais empregado entre os marxistas, mas muitas vezes ele usa o termo "classe" ou "lugar social" como sinônimos. Desta forma, optamos em utilizar o termo "classe" ao longo deste artigo.

6. A Royal Society é uma associação autônoma formada por diversos cientistas do mundo especializados em áreas da ciência, engenharia e medicina que desenvolvem diversas pesquisas.

7. O Jardin des Plantes, originalmente Jardin du Roi, é um dos sete departamentos do Musée National d'Histoire Naturelle, situado na cidade de Paris.

Académie des Sciences é uma academia científica situada na França fundada por Luís XIV com o objetivo de promover a investigação científica francesa.

8. A National Gallery, situada em Londres, abriga a coleção nacional de pinturas na tradição da Europa Ocidental desde o século XIII até o século XIX. Está aberta durante 361 dias por ano e a entrada é gratuita.

9. Victoria and Albert Museum é um museu de artes decorativas localizado em Londres, dispondo de uma coleção permanente de milhares de objetos. 
10. O escritor norte-americano Lyman Frank Baum (1856 - 1919), mais conhecido como L. Frank Baum, foi o autor do livro The Wonderful Wizard of $\mathrm{O} z$ lançado em 1900 e que deu origem ao filme.

11, Technicolor é um processo de coloração de filmes de cinema inventado em 1916 e pertencente à norte-americana Technicolor Motion Picture Corporation. Foi o segundo grande processo de coloração de filmes depois do Kinemacolor da Grã-Bretanha e foi o processo de cor mais usado em Hollywood de 1922 a 1952.

12. There's no place like home (Não há lugar como o lar) era a expressão falada pela personagem Dorothy referindo-se à sua volta ao lar.

13. O American Film Institute (Instituto Americano do Cinema), mais conhecido como $A F I$, é uma organização sem fins lucrativos e independente criada pela National Endowment for the Arts - NEA (Doação Nacional para as Artes), plano estabelecido em 1967 pelo então presidente dos Estados Unidos, Lyndon B. Johnson.

\section{Referências}

BOMFIM, G. A. Coordenadas cronológicas e cosmológicas como espaço das transformações formais. In: COUTO, R. M. de S. et al. Formas do design: por uma metodologia interdisciplinar. Rio de Janeiro: Rio Books, 2014.

BOURDIEU, P. A sociologia de Pierre Bourdieu. Organização: Renato Ortiz. São Paulo: Ática, 1983.

FORTY, A. Objetos de desejo. São Paulo: Cosac Naify, 2007.

KENDRICK; KATHLEEN, M.; LIEBHOLD, P. C. Smithsonian - Treasures of American History. New York: Smithsonian Books e Harper Collinns Publishers, 2006.

ROCHA, E.; FRID, M.; CORBO, W. O paraíso do consumo: Émile Zola, a magia e os grandes magazines. Rio de Janeiro: Mauad X, 2016.

SEGALL, M. L. A. O museu Lasar Segall na década de 70. São Paulo: Edusp, 1991.

\section{Resumo}

A maioria dos museus pelo mundo afora possui lojas que oferecem mercadorias associadas ao que está exposto ou a algum artista específico. O foco de interesse deste artigo é o estudo do campo do Design através do consumo dos objetos associados ao filme O Mágico de Oz que são vendidos nas lojas localizadas no National Museum of American History. Nosso objetivo é compreender tal consumo com base na noção de habitus abordada por Pierre Bourdieu.

\section{Palavras-chave}

Design. Consumo. Mágico. Museu. Habitus.

\section{Abstract}

Most museums around the world have shops that offer products associated with what is on display or to a specific artist. The focus of interest in this paper is the study of the Field of Design through the consumption of objects associated with the film The Wizard of $\mathrm{Oz}$ that are sold in the stores located in the National Museum of American History. Our goal is to understand such consumption based on the notion of habitus approached by Pierre Bourdieu.

\section{Keywords}

Design. Consumption. Magic. Museum. Habitus. 